\title{
Characterization of coronary artery diseases using 256 multi detectors CT scanners
}

\author{
Salma Mohamed Mirghany Abdelmageed ${ }^{1}$, Caroline Edward Ayad ${ }^{2}$, Hanaa Mohamed Alsaqaa ${ }^{1}$, \\ Hythum Salah Mohamed ${ }^{1}$, Elsafi Ahmed Abdalla ${ }^{2}$ \\ ${ }^{1}$ Radiology Department, King Fahad Specialist Hospital, Alqaseem, KSA \\ ${ }^{2}$ College of Medical Radiological Science, Sudan University of Science and Technology, Khartoum, Sudan
}

\section{Email address:}

Salmamohamed@yahoo.com (S. M. M. Abdelmageed), carolineayad@yahoo.com (C. E. Ayad), carolineayad@sustech.edu (C. E.Ayad), Hannamohamed@yahoo.com (H. M. Alsaqaa), Hythumsalah@yahoo.com (H. S. Mohamed), Dr.elsafi@gmail.com (E. A. Abdalla), Dr.elsafi@sustech.edu (E. A. Abdalla)

\section{To cite this article:}

Salma Mohamed Mirghany Abdelmageed, Caroline Edward Ayad, Hanaa Mohamed Alsaqaa, Hythum Salah Mohamed, Elsafi Ahmed Abdalla. Characterization of Coronary Artery Diseases Using 256 Multi Detectors CT Scanners. American Journal of Health Research. Vol. 2, No. 2, 2014, pp. 55-61. doi: 10.11648/j.ajhr.20140202.14

\begin{abstract}
Coronary heart disease is the most common cause of death in the general population. Multi detector Computed Tomography (MDCT) is noninvasive technique and can study the entire coronary-artery tree during a single imaging session. The aims of this study were to characterize coronary arteries in patients who were clinically diagnosed to have coronary artery disease (CAD) using (MDCT) 256 slices, and to compare the findings with other cardiac examinations outcome. The study was done at King Fahad Specialist Hospital-Alqaseem- KSA during the period from January to May 2013 .A total of 102 patients, $63(61.76 \%)$ males, and $39(38.24 \%)$ females were included. All patients with pre-test probability of CAD underwent coronary CT angiography with beta-blockers were administered prior to the scan, and other cardiac investigations were obtained. Patient's age, gender, BMI, weight, Cholesterol level, Hypertension, Diabetes Mellitus, chest pain types, Calcium scoring, were evaluated and correlated with the CT findings and other cardiac investigation results. The evaluated arteries were Left Main Artery (LMA), Left Anterior Descending artery (LAD), Right Coronary Artery (RCA), and Left Circumference Artery (LCA) and were observed for plaques characterization, occlusion or stenosis. A significant association was detected between the CT plaques morphology and BMI, Hyper tension and calcium score at P-value $<0.05$. Patients with normal findings in ECG 53 (57.6\%), Echocardiography 58.0(76.3\%) and Myocardial Perfusion Imaging (MPI) 2(25.0\%) were found to have positive cardiac disease in CTA. Echocardiography is able to characterize Atrial filibration, Heart failure, Ventricle diseases, Valve stenoses and has significant association with gender $P$-value 0.022 and BMI $P$-value 0.042.Myocardial Perfusion Imaging results showed the cardiac function and ejection fraction. No significant association was found between CT findings in coronary arteries and MPI results at P-value 0.789. Coronary CTA disclose diseases in arteries (98.5\%), heart anomalies or valve disease 3(3\%), plaques with significant stenosis $4(4 \%)$, plaque without significant stenosis $11(10.9 \%)$,stenosis without plaques $14(14 \%)$ and total occlusion 1(1\%). In relation to other cardiac tests; cardiac ischemic changes can be detected in ECG, MPI and Echocardiography. Association between CT Plaque Characteristics and Invasive Coronary Arteries results were significant for LAD and RCA at $\mathrm{P}$-value 0.05 . Coronary CTA is a promising non-invasive technique and is highly recommended for characterization of Coronary Arteries and diagnosis the CAD; it could be of great value prior to invasive coronary angiography, although ECG, Echocardiography and MPI(SPECT) are better in studying function.
\end{abstract}

Keywords: 256 MDCT, Coronary Arteries Diseases, Cardiac Imaging

\section{Introduction}

Coronary artery disease (CAD) is the leading cause of death in the United States and other Western countries.[1] Conventional coronary angiography (CA) is currently the reference test for coronary artery lumen assessment, and its use has been steadily increasing over the last decade [1].

Examination of the physiology, perfusion and capability of the heart muscle, morphology of the coronary arteries is significant in the diagnostic assessment of coronary artery disease. The current gold standard to assess the degree of stenotic artery disease is coronary angiography [2]. 
Although coronary angiography has become a safe procedure with only a small associated risk, the difficulties for the patient as well as the economic burden requisite to find an alternative, noninvasive method to characterize and assess coronary arteries [3]. Traditionally, CAD is evaluated indirectly by identifying abnormal regional wall motion and abnormal myocardial perfusion with stress tests and myocardial perfusion scans.[4]These non-invasive tests focused on functional assessment and aimed primarily at indirect identification of flow-limiting coronary artery stenosis. Invasive coronary angiography (ICA) reveals the extent, location, and severity of obstructive lesions and defines therapeutic options.[5]Although both non-invasive and invasive tests can predict outcome, ICA provides direct identification of the coronary arteries. Multi-Detector Computed Tomographic Angiography (CTA) has been used as a non-invasive test to determine the presence and severity of coronary stenosis. For diagnosis of obstructive CAD, multi-detector CTA has been able to replace some of the traditional examinations and avoid the risk caused by invasive procedures of ICA. However, there are several limitations for 64-rowCTA because of substantial amounts of radiation dose, motion artifacts, irregular heartbeats, highly calcified lesions, severe obesity, tachycardia, and routine use of beta-blockers.[6,7]To decrease the CTA drawbacks, new device such as 256- or 320-row CTA was developed. The 320-row CTA can detect more coronary arterial segments and reduce radiation dose. [8]. 256-Row CTA has advantages of faster gantry rotation times, increased X-ray tube power, and larger detector coverage. 256-row CTA provides shorter scanning time, better image quality, and lower radiation dose. [9]

The present study focuses on the clinical role of 256 multislice CT in cardiac imaging, and analyzes findings of Risk factors and pretest probability, as compared with the ECG and Echocardiography, Invasive Coronary Angiography and MPI findings vs. CT findings, and characterize the CAD using 256MDCT.

\section{Materials and Methods}

\subsection{Materials}

The study was conducted at King Fahad Specialist Hospital, Alqaseem, Kingdom of Saudi Arabia (KSA) during the period From January2013 to May 2013.Inclusion Criteria: a total of 102 patients 63(61.8\%) males and $39(38.2 \%)$ females who were clinically diagnosed to have coronary artery disease had undergone coronary artery scanning by the 256 MDCT. Exclusion criteria included acute myocardial infarction, patients at risk for iodinated contrast agents, or elevated serum creatinine $>124 \mathrm{umol} / 1$.

\subsection{Sample Information}

Age, Weight, Chest pain type, and Cardiac Examinations obtained were presented as follows: Patients ages were between (30-75)years old.(30-39) were 7 (6.9\%), (40-49) were 39(38.2\%),(50-59) were $39(38.2 \%)$, (60-69) were $12(11.8 \%)$, and ages equal to or more than 70 were $5(4.9 \%)$. One $(1.0 \%)$ of the sample was under weight, $6(5.9 \%)$ were of normal weight, where 95(82.12\%) were overweight. Eighty $\operatorname{six}(84.3 \%)$ have normal Cholesterol level where 16(15.7\%) have high Cholesterol level. A number of 55(53.9\%) of the sample were complaining of Diabetes Mellitus and the other $47(46.1 \%)$ were considered normal. Sixty (58.8\%) were with hypertension and 42(41.2\%) were normal. After applying the pre-test probability and classifying according to age and gender, it was found that the sample of high probability was found to be $7(6.9 \%)$, intermediate $80(78.4 \%)$ and of low probability were $15(14.7 \%)$.Signs as chest pain were appraised into typical and a-typical pain, 23(22.5\%) came with a- typical chest pain where $79.0(77.5 \%)$ have Typical chest pain. Among those, 92 patients were examined for ECG, 76 patients were examined for Echocardiography, 8 patients were requested to Myocardial Perfusion Imaging (MPI) using SPECT, and 17 patients were requested to do an additional Invasive coronary angiography (ICA) by their cardiologists.

\subsection{CT Technique and Methods of Patients' Evaluation}

Contrast-enhanced computed tomography (CT) studies of the coronary arteries were performed first to visualize the vessel lumen and to achieve an angiographic-like presentation of the coronary arteries in combination with 3D post processing methods. For morphological assessment of cardiac structures, scan protocol used were 100-ms exposure time, 0.6-3-mm slice thickness, and $130-\mathrm{kVp}, 630-\mathrm{mA}$.

The acquisition of every single slice was triggered prospectively by the electrocardiogram (ECG) signal at the end systolic phase of the cardiac cycle, and was operated with retrospective ECG gating. The ECG trace is recorded simultaneously during the scan acquisition. The X-ray projections of the mid-diastolic phase are selected to reconstruct images from the slow-motion diastole phase of the heart.

For patients preparation, Caffeine and drugs that increases the heart rate were avoided prior to the cardiac CTA investigation. When $\beta$-blocker was used, patients with bronchial asthma, AV block, severe congestive heart failure, aortic stenosis, were contraindicated and have to be ruled out .An informed consent was obtained from the patients. In cases where the heart rate of the patients was above $60 \mathrm{bpm}$, 20-80 mg of Metoprololtartrat was administered intravenously immediately prior to scanning. Monitoring of vital functions (heart rate and blood pressure) were checked.

Contrast media used was Iodinated contrast media (XENETIX 350 (350 MGI/ML))(60-80 ml) $5 \mathrm{cc}$ per second .

Axial CT images and post processing techniques including maximum intensity projections (MIP), shaded surface display (SSD), and volume-rendering technique (VRT) were used. The segmentation of the sternum, the ribs, and the vertebral column were done. The auricle of the left atrium was segmented to gain access to the left main coronary artery. Standardized projection views around the long axis of the heart were taken to allow for display of the 
superficial course of all three major coronary arteries. Standardized thin ( $3 \mathrm{~mm}$ ) MIP slices with 1.5-mm increment between the slices were reconstructed in three different planes.MIP in the right anterior oblique plane was taken to display the course of the LAD.MIP in the left anterior oblique plane was taken to display the course of the right and circumflex coronary artery .

\subsection{Acquisition and Analysis of Data from other Cardiac Imaging Methods}

The Acquisition and analysis of data from invasive coronary angiography were performed using standard techniques for quantitative coronary angiography (QCA). The angiograms were interpreted by two cardiologists both had over 5-year experience of cardiac catheterization.

The Acquisition and analysis of data in Echocardiography was done for Patients in the left lateral decubitus position using a commercially available system (General ElectricVingmed, Milwaukee, Wisconsin, USA). Images were obtained using a $3.5-\mathrm{MHz}$ transducer, at a depth of $16 \mathrm{~cm}$ in the parasternal and apical views (standard parasternal longand short-axis, apical 2- and 4-chamber images.

\subsection{Method of Evaluation}

The patients Age ,BMI ,Heart Rate, Cholesterol ,diabetes mellitus, hypertension ,Calcium Score , and signs were detected and were evaluated, the arteries including Left Main Artery, Left Anterior Descending artery ,Right Coronary Artery, Left Circumference Artery were characterized for CAD according to the CT outcome regarding the plaques character (soft, mixed, calcified) or the presence of stenosis ,occlusion, anomalies as well as the normal findings. The Association between CT-Findings, risk factor and patient's demographic data were evaluated. The patients who underwent electrocardiograph (ECG) were 92 (out of 102 patients who were examined by CT)their findings were classified as the absence, or presence of ischemic changes including(Anterio -lateral Ischemic Change, Anterior Ischemic Change, Inferior superior ischemic changes , Inferio-anterior Ischemic Change ,Inferio- lateral Ischemic Change, Inferior Ischemic Change. The patients who underwent echocardiography were 76 patients and their characterization were according to their findings including Atrial filibration, Heart failure, ventricle abnormalities, Valve stenosis, or normal.

Only 8 out of 102 were recommended for (Myocardial Perfusion Imaging) using SPECT and their characterization were according to the site of disease including apical, apical and wall, wall only as well as the normal perfusion findings. 17 out of 102 were requested for invasive coronary angiography (ICA) and the characterization was according to the examination outcome including normal findings, anomalous arteries, positive diseases. The data were collected in master data sheet, SPSS programme version16 was used to analyze the data statistically .Values are expressed as Mean \pm STDV. The association between patients demographic data, clinical signs, risk factors and CT findings with the other cardiac examinations results were studied. Significant relations were considered at $\mathrm{P}$-value $<0.05$.

\section{Results}

The following tables present the data as follows:

Table (1). Descriptive Statistics.

\begin{tabular}{llll}
\hline Variable & Mean $\pm \mathbf{S ~ D}$ & Minimum & Maximum \\
\hline Age & $51.6 \pm 8.8$ & 35.0 & 81.0 \\
BMI & $29.2 \pm 5.7$ & 30.0 & 48.5 \\
Heart Rate & $63.9 \pm 10.0$ & 35.0 & 87.0 \\
Cholesterol & $5.7 \pm 7.4$ & 1.0 & 60.0 \\
Calcium Score & $64.4 \pm 240.1$ & 0.0 & 1475.0 \\
\hline
\end{tabular}

Table (2). Association between Risk factors and patient's demographic data with sign as typical and a-typical chest pain.

\begin{tabular}{ll}
\hline $\begin{array}{l}\text { Risk factors and patients demographic } \\
\text { data with chest pain type(signs) }\end{array}$ & (P-value) \\
\hline Age & 0.178 \\
Gender & 0.173 \\
BMI & 0.440 \\
Cholesterol & 0.692 \\
Diabetes Mellitus & $0.036^{*}$ \\
Hypertension & 0.462 \\
Pretest Probability & 0.821 \\
Heart Rate & 0.964 \\
Calcium Score & 0.577 \\
\hline
\end{tabular}

Values are expressed as Mean $\pm \mathrm{SD} ;{ }^{*}$ Significant at $\mathrm{P}$-value $<0.05$.

Table (3). Distribution of the study sample according to the affected arteries: Left Main Artery (LMA), Left Anterior Descending artery (LAD), Right Coronary Artery (RCA), and Left Circumference Artery (LCX) as seen in Computerized Tomography Coronary angiography (CTA)

\begin{tabular}{lllll}
\hline Outcome Plaque & Artery & & & \\
Character & LMA & LAD & RCA & LCA \\
Anomalous & 0 & 1 & 0 & 2 \\
Arteries & $(0.0 \%)$ & $(1.0 \%)$ & $(0.0 \%)$ & $(2.0 \%)$ \\
Calcium Plaque & 3 & 4 & 5 & 5 \\
Calcium Plaque \& & $(3.0 \%)$ & $(3.9 \%)$ & $(4.9 \%)$ & $(4.9 \%)$ \\
Stenosis & 0 & 5 & 0 & 4 \\
Mixed Plaque & $(0.0 \%)$ & $(4.9 \%)$ & $(0.0 \%)$ & $(3.9 \%)$ \\
Mixed Plaque \& & 2 & 6 & 3 & 2 \\
Stenosis & $(2.0 \%)$ & $(5.9 \%)$ & $(2.9 \%)$ & $(2.0 \%)$ \\
Normal & $(2.0 \%)$ & $(12.8 \%)$ & $(2.9 \%)$ & $(3.9 \%)$ \\
& 83 & 61 & 81 & 79 \\
Soft Plaque & $(82.2 \%)$ & $(59.8 \%)$ & $(79.4 \%)$ & $(77.5 \%)$ \\
Soft Plaque \& & 6 & 3 & 2 & 1 \\
Stenosis & $(5.9 \%)$ & $(2.9 \%)$ & $(2.0 \%)$ & $(1.0 \%)$ \\
Stenosis & $(2.0 \%)$ & $(4.9 \%)$ & $(2.9 \%)$ & $(2.0 \%)$ \\
& 3 & 4 & 4 & 3 \\
Occlusion & $(3.0 \%)$ & $(4.0 \%)$ & $(4.0 \%)$ & $(3.0 \%)$ \\
& 0 & 0 & 1 & 0 \\
\hline
\end{tabular}

$98.5 \%$ were diagnosed to have coronary artery diseases. Plaque with significant stenosis 4(4\%) in LMA, 23(22.6\%) in LAD, 6(5.8\%) in RCA.10 $(9.8 \%)$ in LCA .Plaque without significant stenosis $11(10.9 \%$ )in LMA, 13(12.7) in LAD, 10(9.8\%) in RCA,8( 7.9\%)in LCA. Stenosis without plaques was found to be present in 14 arteries (14\%) where the total occlusion was present in $1(1 \%)$ RCA 
Table (4). Association between CT-Finding (Plaque Character) Risk factor and patient's demographic data.

\begin{tabular}{lc}
\hline Risk factor and patient's demographic data & (P-value) \\
\hline Age & 0.550 \\
Gender & 0.351 \\
BMI & $0.041^{*}$ \\
Cholesterol & 0.149 \\
Diabetes Mellitus & 0.308 \\
Hypertension & $0.006^{*}$ \\
Pretest Probability & $0.032^{*}$ \\
Heart Rate & 0.518 \\
Calcium Score & $0.044^{*}$ \\
\hline
\end{tabular}

Values are expressed as Mean $\pm \mathrm{SD} ;{ }^{*}$ Significant at $\mathrm{P}$-value $<0.05$.

Table (5). Distribution of the study sample according to (Electrocardiography findings: Ischemic Changes Sites).

\begin{tabular}{lll}
\hline Electrocardiography & Frequency & Percentage\% \\
\hline Anteriolateral Ischemic Change & 6 & $6.5 \%$ \\
Anterior Ischemic Change & 4 & $4.3 \%$ \\
Inferio Superior Ischemic Change & 1 & $1.1 \%$ \\
Inferioanterior Ischemic Change & 1 & $1.1 \%$ \\
Inferiolateral Ischemic Change & 7 & $7.6 \%$ \\
Inferior Ischemic Change & 20 & $21.7 \%$ \\
No Ischemic Change & 53 & $57.6 \%$ \\
Total & 92 & $100.0 \%$ \\
\hline
\end{tabular}

Table (6). Distribution of the study sample according to (Echocardiography results: heart and valve).

\begin{tabular}{lll}
\hline Echocardiography & Frequency & Percentage \\
\hline Atrial filibration & 1.0 & $1.3 \%$ \\
Heart failure/ ventricle diseases & 15.0 & $19.7 \%$ \\
Normal & 58.0 & $76.3 \%$ \\
Valve stenosis & 2.0 & $2.6 \%$ \\
Total & 76.0 & $100.0 \%$ \\
\hline
\end{tabular}

Table (7). Association between ECHO Findings, patient's demographic data Risk factor.

\begin{tabular}{lc}
\hline $\begin{array}{l}\text { Association between ECHO results, patient's } \\
\text { demographic data and Risk factor }\end{array}$ & (P-value) \\
\hline Age & 0.332 \\
Gender & $0.022^{*}$ \\
BMI & $0.042^{*}$ \\
Cholesterol & 0.432 \\
Diabetes Mellitus & 0.374 \\
Hypertension & 0.145 \\
Pretest Probability & 0.085 \\
\hline
\end{tabular}

Almost PTs with normal finding in ECHO have positive cardiac disease. Echo findings include mild dilated right ventricle, mild dilated left ventricular hypertrophy, diastolic failure ,mild mitral regurgitation, tricuspid regurgitation, grade 1 pulmonary valve stenosis, grade 1 diastolic dysfunction, grade 2 diastolic dysfunction, left bundle branch block, left ventricular failure, atrial fibrillation

Table (8). Association between Ejection Fraction (EF) and patient's demographic data.

\begin{tabular}{ccccc}
\hline $\begin{array}{c}\text { Correlations } \\
\text { Correlation }\end{array}$ & Age & BMI & $\begin{array}{c}\text { Heart } \\
\text { Rate }\end{array}$ & Cholesterol \\
$\begin{array}{c}\text { Coefficient } \\
\text { P-value }\end{array}$ & -0.290 & -0.002 & -0.124 & 0.120 \\
\hline
\end{tabular}

*P-value is significant at 0.05
Table (9). Association between chest pain \& Pretest Probability (P-value $=$ $0.821)$.

\begin{tabular}{cccc}
\hline Pretest & \multicolumn{2}{c}{ Chest pain } & Total \\
Probability & A-typical & Typical & \\
\hline High & $1(14.3 \%)$ & $6(85.7 \%)$ & $7(100.0 \%)$ \\
Intermediate & $19(23.8 \%)$ & $61(76.3 \%)$ & $80(100.0 \%)$ \\
Low & $3(20.0 \%)$ & $12(80.0 \%)$ & $15(100.0 \%)$ \\
Total & $23(22.5 \%)$ & $79(77.5 \%)$ & $102(100.0 \%)$ \\
\hline
\end{tabular}

Table (10). Distribution of the study sample according to (Myocardial Perfusion Imaging SPECT).

\begin{tabular}{ccc}
\hline Myocardial Perfusion Imaging & Frequency & Percentage\% \\
\hline Apical & 2.0 & $25.0 \%$ \\
Apical \& Wall & 2.0 & $25.0 \%$ \\
Normal & 2.0 & $25.0 \%$ \\
Wall & 2.0 & $25.0 \%$ \\
Total & 8.0 & $100.0 \%$ \\
\hline
\end{tabular}

Table (11). Distribution of the study sample according to $L M, L A D, R C A$, and LCX diagnosed by invasive coronary angiography (ICA).

\begin{tabular}{ccccc}
\hline Outcome & LMA & LAD & RCA & LCX \\
\hline $\begin{array}{c}\text { Anomalous } \\
\text { arteries }\end{array}$ & $0(0.0 \%)$ & $1(5.9 \%)$ & $0(0.0 \%)$ & $1(5.9 \%)$ \\
$\begin{array}{c}\text { Normal } \\
\text { Arteries }\end{array}$ & $9(56.3 \%)$ & $5(29.4 \%)$ & $7(41.2 \%)$ & $4(23.5 \%)$ \\
$\begin{array}{c}\text { Positive } \\
\text { disease }\end{array}$ & $7(43.8 \%)$ & $11(64.7 \%)$ & $10(58.8 \%)$ & $12(70.6 \%)$ \\
\hline
\end{tabular}

Table (12). Association between CT - Finding (Plaque Characteristics) \& (Invasive Coronary Artery Results) (P-value 0.05)*.

\begin{tabular}{ccccc}
\hline & LMA & LAD & RCA & LCA \\
\hline $\begin{array}{c}\text { CT findings(Plaque } \\
\text { Characteristics) }\end{array}$ & 0.900 & $0.000^{*}$ & 0.897 & 0.734 \\
$\begin{array}{c}\text { (Invasive Coronary } \\
\text { Artery (Results) }\end{array}$ & 0.075 & 0.068 & $0.007 *$ & 0.064 \\
\hline
\end{tabular}

\section{Discussion}

Computed Tomographic Angiography using 256 MD slice was considered medically necessary for the evaluation of chest pain syndrome in patients with intermediate pre-test probability of Coronary Arteries Diseases by Framingham risk scoring 10] or by American College of Cardiology criteria[11] . Regarding the rules; the patients whose ages were $51.6 \pm 8.8$, heart rate $63.9 \pm 10.0$, BMI $29.2 \pm$ 5.7Calcium Score mean values $64.4 \pm 240.1$ with maximum Agatston of 1475.0 were enrolled in the study as presented in table(1)

In our study, the association between signs, risk factors and patient demographic data were found to be significant with Diabetes Mellitus as presented in table (2). The findings were consigned with the fact that risk factors including Cigarette Smoking, Hypertension, Elevated Low-Density Lipoprotein (LDL) Cholesterol, Low HDL Cholesterol, Diabetes Mellitus, and advancing age are clearly related to extent of coronary atherosclerosis and to the risk of clinical CHD events. All, except advancing age were believed to be direct causes of coronary atherosclerosis [13].

The severity of disease, location, anatomy and stenosis were assessed accurately by 256-row CT. It showed, Left 
main arteries were found to be normal in 83 patients of the sample where 18 arteries were affected with different plaques types .Sixty one LAD arteries were found to be normal and forty one arteries were affected with plaques, Eighty one RCA were normal and Twenty one were affected with plaques, Seventy nine LCA were normal and, twenty three were affected with plaques, this was presented in table (3).

CTA characterized the plaques as calcium plaque, soft plaque, mixed plaque, calcium plaque with stenosis ,soft plaque with stenosis, mixed plaque with stenosis, stenosis without plaque and total occlusion. The higher frequency of the affected patients with CAD in the sample were 39 (38.2\%) with ages were in the cluster of(40-49) and(50-59)years old .This information in addition to the data presented in table (4), that mentioned that the risk factors and patients demographic data including ,BMI, Hyper tension, Pretest probability and calcium score values had significant relation with the CT diagnosis and findings at $\mathrm{P} \square 0.05$ were consigned with the fact that the Coronary arterial calcification is part of the development of atherosclerosis.[14 -17] and that the Coronary artery calcification occurs in small amounts in the early lesions of atherosclerosis that appear in the second and third decades of life and was found more frequently in older age[18]. There is a positive correlation between the site and the amount of coronary artery calcium and the coronary luminal narrowing at the same anatomic site [18].This was similar to was detected in our study. Anomalous arteries in the sample are rare, but CTA detected it in one Right Coronary Artery, and in 2 Left Circumference Arteries of the sample. Invasive Coronary Angiography (ICA) got the similar findings as seen in table(11), but one of the 2 left circumference arteries anomalies was not detected; as mentioned in the findings that anomalous coronary arteries are an uncommon finding during angiography, occurring in approximately $1 \%$ of coronary angiograms completed for evaluation of chest pain. However, these congenital anomalies can be clinically important depending on the course of the anomalous arteries. A number of case series have consistently reported that coronary CTA is able to delineate the course of these anomalous arteries, even when conventional angiography cannot. [19-21].Regarding the study results; and when anomalous coronary arteries require evaluation in symptomatic patients, coronary CTA was found to be beneficial than the invasive angiography. It has been demonstrated that CTA can define the anatomy of anomalous vessels when angiography is unclear. Thus, CTA may be considered medically necessary for evaluating anomalous coronary arteries.

In our study functional tests were obtained; because for patients with suspected Coronary Artery Disease; the preliminary noninvasive test in a diagnostic treatment strategy was always functional, and the choice of the test is based on clinical factors such as gender, ECG abnormalities, and chest pain characteristics.[12] The ECG was done for 92 of the sample although the patients has chest pain and were diagnosed to have coronary artery diseases, the findings were found to be Ischemic Changes at different sites including:Anterior, Inferio Superior, Inferioanterior, Inferiolateral ,Inferior, Anterio-lateral, but the majority 53 $(57.6 \%)$ have no ischemic changes and have normal ECG results this was presented in table(5)

Echocardiography was requested for 76 patients of the sample, their findings were Atrial filibration, Heart failure, ventricle diseases, Valve stenosis but 58 have normal echo results. Echocardiography showed significant relation with gender $P$-value is 0.022 and BMI 0.042 but no significant association was detected with the other risk factors including Cholesterol level, Diabetes Mellitus Hypertension, Pretest Probability this appear in the tables(6,7, 8).Echocardiography showed different morphologies of cardiac problems including the mild dilated right ventricle, mild dilated left ventricular hypertrophy, diastolic failure ,mild mitral regurgitation, tricuspid regurgitation, grade 1 pulmonary valve stenosis, grade 1 diastolic dysfunction, grade 2 diastolic dysfunction, left bundle branch block, left ventricular failure, atrial fibrillation .The high pretest probability results were found in patients either with normal ECG (5 patients out of 7), or with left bundle branch block (1 patient) or with mild dilated LVH (1patient) .Table (9) showed the relation between the chest pain type and pre test probability. Association between Ejection Fraction (EF) and patient's demographic data was found to be significant with age. Echocardiography is found to be useful in the assessment of LV function. Which may accurately be evaluated by CT (in the same session, without need for additional contrast), and can be added when noninvasive angiography with MDCT is performed.

Myocardial Perfusion Imaging (SPECT) done for 8 of the patients showed the sites of the lesions in the apical part of the heart, apical and wall or in the cardiac wall only, 6 patients were diseases and 2 were normal. Its character was described as apical hypo perfuse segment, sever ischemic change in anterior wall, mild ischemic change in anterior apex and wall as presented in table (10). Six patients were of high pretest probability and the other 4 were of intermediate pretest probability.

Invasive coronary angiography showed positive diseases findings in Left Main Artery 7(43.8\%) ,Left Anterior Descending 11(64.7\%), Right Coronary Artery10 (58.8\%) ,Left Circumference Artery12 (70.6\%) as presented in table(11). The Association between CT-Findings (Plaque Characteristics) and (Invasive Coronary Artery Results) were found to be significant ( $P$-value 0.05$)$ for Left Anterior Descending artery and Right Coronary Artery as noted in table (12).Patients with doubtful findings were referred to invasive angiography. Assessment by Coronary Computed Tomography Angiography (CCTA) of Individuals undergoing Invasive Coronary Angiography ICA were obtained in 17 patients and showed significant results in Left Anterior Descending arteries and Right Coronary Arteries . CTA can characterize the plaques type in all Left Main and Left Circumference Arteries as mixed, soft, or calcified plaques with or without stenoses.The importance of the 
invasive angiography is that when the disease is detected, treatment alternatives include medical therapy or revascularization (PCI or $\mathrm{CABG}$ ) were decided. Which approach to adopt is based on the extent of anatomic disease, symptom severity, and evidence of ischemia from functional testing, noninvasive testing or more recently fractional flow reserve obtained during invasive angiography [12]

Advances in MDCT have made imaging of the coronary arterial lumen and wall feasible ,making CT angiography (CTA) an appropriate clinical tool for the evaluation of suspected coronary artery disease (CAD) in patients with a low-to-intermediate possibility of disease ,this was similar to what was found in the previous studies[22,23-25]. The main advantages of CTA are its noninvasive nature, compared with conventional coronary angiography, as found in several previous studies [26-30]. Although CTA is a sensitive method for detecting atherosclerosis, it is limited in its ability to predict the physiologic significance of coronary luminal stenosis this was also found in the study done earlier $[31,32]$ and also Multiple studies have shown that coronary luminal stenosis identified by CTA is a poor predictor of reversible ischemia, [31-34]. Therefore ECG, Myocardial Perfusion SPECT were performed, and the Ischemic changes at different sites were detected well in ECG . The importance of detection of myocardial ischemia is that it has significant implications in the diagnosis, prognosis, and treatment of patients with CAD [35-38].Coronary CTA is capable in determining the percentage of luminal stenosis and determining the constituents of plaque. However, in its current form, it does not provide important information on the physiologic significance of coronary stenosis.

\section{Conclusion}

The study concluded that Coronary CTA is considered as one of the most important advances in the noninvasive diagnosis of $\mathrm{CAD}, 256$-row CTA is a high responsive diagnostic tool for characterization $\mathrm{CAD}$ and may be better than the Invasive Coronary Angiography (ICA) in the characterization of coronary artery diseases .Although SPECT and Echocardiography and ECG are better is studying the cardiac function

\section{Acknowledgements}

Many thanks to King Fahad Specialist Hospital, Alqaseem, KSA and College of Medical Radiological Science, Sudan University of Science and Technology, to allow the authors to perform this work.

\section{References}

[1] T .Thom, N. Haase, W .Rosamond, "Heart disease and stroke statistics - 2006 update: a report from the American Heart Association Statistics Committee and Stroke Statistics Subcommittee". Circulation 2006; 14:113: 85-151.
[2] F. Kopp,A .Kuttner, ,T. Trabold, M .Heuschmid, S .Schro“ Der, ,C. D .Claussen, Multi slice CT in cardiac and coronary angiography, The British Journal of Radiology, 77 (2004), S87-S97 E 2004 The British Institute of Radiology DOI: $10.1259 /$ bjr $/ 30634988$

[3] B.W .Kwok, T.T. Lim. Cortical blindness following coronary angiography. Singapore Med J 2000; 41:604-5.

[4] D.S .Berman, R .Hachamovitch, L.J .Shaw, J.D. Friedman, S.W .Hayes, L.E .Thomson, D.S .Fieno, G .Germano, N.D Wong, X .Kang, A .Rozanski. Roles of nuclear cardiology, cardiac computed tomography, and cardiac magnetic resonance: noninvasive risk stratification and a conceptual framework for the selection of noninvasive imaging tests in patients with known or suspected coronary artery disease.J Nucl Med 2006;47:1107-1118.

[5] PJ Scanlon, DP Faxon, AM Audet, B Carabello, GJ Dehmer, KA Eagle, RD Legako, DF Leon, JA Murray, SE Nissen, CJ Pepine, RM Watson, JL Ritchie, RJ Gibbons, MD Cheitlin, TJ Gardner, A Jr Garson, RO Jr Russell, TJ Ryan, SC Smith Jr.ACC/AHA Guidelines for coronary angiography. J Am Coll Cardiol 1999;33:1756-1824.

[6] S .Prat-Gonzalez, J .Sanz, M. Garcia. Cardiac CT: indications and limitations. J NuclMed Technol 2008;36:18-24

[7] S .Voros. What are the potential advantages and disadvantages of volumetric CT Scanning.J Cardiovasc Comput Tomogr 2009;3:67-70

[8] FJ. Rybicki, HJ. Otero, MI Steigner, G Vorobiol, Nallamshetty 1, D Mitsouras, H Ersoy, RT Mather, PF Judy, Cai T, Coyner K, K Schsultz, AG Whitmore, MF DiCarli. Initial evaluation of coronary images from 320-detector row computedtomography. Int $\mathrm{J}$ Cardiovasc Imaging 2008;24:535-546

[9] WG Weigold, ME Olszewski, MJ Walker. Low-dose prospective gated 256-slice Coronary computed tomographic angiography. Int J Cardiovasc Imaging 2009;25:217-230

[10] Current guidelines from the American Heart Association recommend against routine stress testing for screening asymptomatic adults

[11] Estimate of 10-Year Risk for Coronary Heart Disease Framingham Point Scores, available at http://www.nhlbi.nih.gov/guidelines/cholesterol/risk_tbl.htm

[12] Robert A. O'Rourke, Bruce H. Brundage, ,Victor F. Froelicher, , Philip Greenland, Scott M. Grundy, ,Rory Hachamovitch, , Gerald M. Pohost, , Leslee J. Shaw, William S. Weintraub, William L. Winters, American College of Cardiology/American Heart AssociationExpert Consensus Document on Electron-Beam ComputedTomography for the Diagnosis and Prognosis of Coronary Artery Disease.February 2000. This document is available on the Web sites of the American College of Cardiology (www.acc.org) and theAmerican Heart Association (www.americanheart.org). (J Am Coll Cardiol 2000;36:326-40)(C 2000 American College of Cardiology and American Heart Association, IncPII S0735-1097(00)00831-7.

[13] SM Grundy. Age as a risk factor: you are as old as your arteries. Am J Cardiol 999;83:1455-7.

[14] R Ross. The pathogenesis of atherosclerosis: a perspective for the 1990s. Nature 1993;362:801-9 
[15] HC Stary. Composition and classification of human atheroscleroticlesions. Virchows Arch A Pathol Anat Histopathol 1992;421:277-90

[16] HC Stary, AB Chandler, RE Dinsmore, et al. A definition of advanced types of atherosclerotic lesions and a histological classification of atherosclerosis: a report from the Committee on Vascular Lesions of the Council on Arteriosclerosis, American Heart Association. Circulation 1995;92:1355-74

[17] SR Tanenbaum, GT Kondos, KE Veselik, Prendergast MR, BH Brundage, EV Chomka. Detection of calcify deposits in coronary arteries by ultrafast computed tomography and correlation with angiography.Am J Cardiol 1989;63:870 -2

[18] RF Berbarie, WD Dockery, Johnson KB et al. Use of multislice computed tomographic coronary angiography for the diagnosis of anomalous coronary arteries. Am J Cardiol 2006; 98(3):402-6.

[19] J Datta, CS White, RC Gilkeson et al. Anomalous coronary arteries in adults: depiction at multi-detector row CT angiography. Radiology $2005 ; 235(3): 812-8$

[20] S Romano, A Morra, M Del Borrello et al. Multi-slice computed tomography and the detection of anomalies of coronary arteries. J Cardiovasc Med (Hagerstown) 2008; $9(2): 187-94$

[21] R Schmitt, S Froehner, J Brunn et al. Congenital anomalies of the coronary arteries: imaging with contrast-enhanced, multidetector computed tomography. Eur Radiol 2005; 15(6):1110-21

[22] GL Raff, MJ Gallagher, WW O’Neill, JA Goldstein. Diagnostic accuracy of noninvasive coronary angiography using 64-slice spiral computed tomography. J Am Coll Cardiol. 2005; 46:552-557

[23] P Greenland. Who is a candidate for noninvasive coronary angiography. Ann Intern Med. 2006;145:466-467

[24] JE Jacobs, LM Boxt, Desjardins B, Fishman EK, Larson PA, Schoepf J. ACR practice guideline for the performance and interpretation of cardiac computed tomography (CT). J Am Coll Radiol. 2006;3:677-685

[25] MJ Budoff, S Achenbach, RS Blumenthal, et al. Assessment of coronary artery disease by cardiac computed tomography: a scientific statement from the American Heart Association Committee on Cardiovascular Imaging and Intervention, Council on Cardiovascular Radiology and Intervention, and Committee on Cardiac Imaging, Council on Clinical Cardiology. Circulation. 2006; 114:1761-1791

[26] MJ Budoff, D Dowe, JG Jollis, et al. Diagnostic performance of 64-multidetector row coronary computed tomographic angiography for evaluation of coronary artery stenosis in individuals without known coronary artery disease: results from the prospective multicenter ACCURACY (Assessment by Coronary Computed Tomographic Angiography of Individuals Undergoing Invasive Coronary Angiography) trial. J Am Coll Cardiol. 2008; 52:1724-1732

[27] MJ Garcia, J Lessick, Hoffmann MH. Accuracy of 16-row multidetector computed tomography for the assessment of coronary artery stenosis. JAMA. 2006; 296:403-411

[28] WB Meijboom, MF Meijs, JD Schuijf, et al. Diagnostic accuracy of 64-slice computed tomography coronary angiography: a prospective, multicenter, multivendor study. J Am Coll Cardiol. 2008; 52:2135-2144

[29] JM Miller, CE Rochitte, M Dewey, et al. Diagnostic performance of coronary angiography by 64-row CT. N Engl J Med. 2008; 359:2324-2336

[30] G Mowatt, JA Cook, GS Hillis, et al. 64-Slice computed tomography angiography in the diagnosis and assessment of coronary artery disease: systematic review and meta-analysis. Heart. 2008; 94:1386-1393

[31] GM Schuetz, NM Zacharopoulou, P Schlattmann, M Dewey. Meta-analysis: noninvasive coronary angiography using computed tomography versus magnetic resonance imaging. Ann Intern Med.2010; 152:167-177

[32] MF Di Carli, S Dorbala, Z Curillova, et al. Relationship between CT coronary angiography and stress perfusion imaging in patients with suspected ischemic heart disease assessed by integrated PET-CT imaging. J Nucl Cardiol. 2007; 14:799-809

[33] JD Schuijf, W Wijns, JW Jukema, et al. Relationship between noninvasive coronary angiography with multi-slice computed tomography and myocardial perfusion imaging. J Am Coll Cardiol. 2006; 48:2508-2514

[34] M Hacker, T Jakobs, F Matthiesen, et al. Comparison of spiral multidetector CT angiography and myocardial perfusion imaging in the noninvasive detection of functionally relevant coronary artery lesions: first clinical experiences. J Nucl Med. 2005; 46:1294-1300

[35] S Rispler, Z Keidar, E Ghersin, et al. Integrated single-photon emission computed tomography and computed tomography coronary angiography for the assessment of hemodynamically significant coronary artery lesions. J Am Coll Cardiol. 2007; 49:1059-1067

[36] Hachamovitch R, Berman DS, Shaw LJ, et al. Incremental prognostic value of myocardial perfusion single photon emission computed tomography for the prediction of cardiac death:differential stratification for risk of cardiac death and myocardial infarction. Circulation. 1998;97:535-543

[37] R Hachamovitch, SW Hayes, JD Friedman, I Cohen, DS Berman. Comparison of the short-term survival benefit associated with revascularization compared with medical therapy in patients with no prior coronary artery disease undergoing stress myocardial perfusion single photon emission computed tomography. Circulation. 2003; 107:2900-2907

[38] AS Iskandrian, SC Chae, J Heo, CD Stanberry, V Wasserleben, $\mathrm{V}$ Cave. Independent and incremental prognostic value of exercise single-photon emission computed tomographic (SPECT)thallium imaging in coronary artery disease. J Am Coll Cardiol. 1993; $22: 665-670$. 